\title{
Estudio florístico del Area Marina Costera Protegida Francisco Coloane, Región de Magallanes, Chile
}

\section{Floristic study of the Francisco Coloane Coastal Marine Protected Area, Región de Magallanes, Chile}

\author{
Erwin Domínguez ${ }^{1} \&$ Juan Carlos Aravena² \\ ${ }^{1}$ Instituto de Investigaciones Agropecuarias - INIA - CRI - Kampenaike. Casilla 277, Punta Arenas, Chile. \\ ${ }^{2}$ Centro de Estudios del Cuaternario de Fuego-Patagonia (CEQUA). Casilla 737, Punta Arenas, Chile. \\ edominguez@inia.cl
}

\begin{abstract}
RESUMEN
Un factor clave para generar políticas de conservación y de manejo de un área protegida es el conocimiento detallado de su biodiversidad. En este trabajo documentamos la flora vascular del Área Marina Costera Protegida Francisco Coloane representada por 55 familias, 92 géneros y 120 especies. De ellas 69 son endémicas para Chile y Argentina. Las familias más diversas son: Asteraceae (11 géneros/15 especies), Poaceae (10/13) y Cyperaceae (6/12). Los géneros mejor representados son Carex con 5 especies y Senecio con 4, mientras que 72 géneros están representados por una sola especie. La forma de vida dominante son las hierbas ( 74 especies, 62\%), seguidas de los subarbustos (19 especies, 16\%). Dos especies son nuevos registros para la Región de Magallanes (Lupinus arboreus y Gamochaeta monticola). E1 95\% de la flora corresponde a especies nativas y un 5\% a especies introducidas naturalizadas. Sólo 9 especies presentan problemas de conservación.
\end{abstract}

Palabras clave: Flora de Chile, conservación, plantas introducidas, flora vascular.

\begin{abstract}
A detailed knowledge of protected areas biodiversity is a key factor to generate preservation and management policies. A survey on the vascular flora of Francisco Coloane Coastal Marine Protected Area is examined in this paper. The flora is represented by 55 families, 92 genera and 120 species. 69 of them are endemic for Chile and Argentina. The most diverse families are Asteraceae (11 genera/15 species), Poaceae (10/13) and Cyperaceae (6/12). The genera with highest number of species are Carex and Senecio with 5 and 4 species, respectively; while 72 genera are represented by only one species. The dominant life form is herbaceous plants (74 species, 62\%), followed by the sub schrubs (19 species, 16\%). Two species constitute new records for Magallanes Region (Lupinus arboreus and Gamochaeta monticola). The 95\% of the flora corresponds to native species and only 5\% are exotic plants. Only 9 of 120 species have the status of endangered species.
\end{abstract}

KEYwORDs: Flora of Chile, conservation, exotic plants, vascular flora.

\section{INTRODUCCIÓN}

Toda política ambiental para la identificación de áreas de conservación debe estar basada en un exhaustivo examen de su flora (Chiarucci \& Bonini 2005), considerando que los elementos florísticos constituyen importantes bioindicadores para la evaluación de su estado de conservación y los efectos del manejo de sus ecosistemas (Qian 1999, Secretariat of the Convention on Biological Diversity 2008). De esta manera se puede monitorear las variaciones de abundancia, diversidad, nivel de vulnerabilidad y las especies con problemas de conservación, información necesaria para desarrollar un plan de gestión ambiental (Parks Canadá 1997, Núñez 2008).

El Grupo Técnico Experto sobre Áreas Marinas Costeras Protegidas (AHTEG según sus siglas en inglés) del Convenio sobre Diversidad Biológica de 1993, acuñó el término Área Marina Costera Protegida (AMCP) y lo definió como "una área dentro de o adyacente al ambiente marino, junto con sus aguas, flora, fauna, y características históricas asociadas, la cual ha sido reservada por legislación $\mathrm{u}$ otros medios efectivos, incluyendo las costumbres, con el 
propósito que la biodiversidad marina y/o costera goce de un nivel de protección más alto que en sus alrededores". Las áreas marinas costeras protegidas han sido creadas por la necesidad de proteger y preservar los ecosistemas frágiles, vulnerables o de valor natural o cultural único, con particular énfasis en la flora y fauna amenazadas de agotamiento y extinción, y a la vez, promover actividades económicas de bajo impacto ambiental que permitan dar sustentabilidad a las actividades de conservación, investigación, educación y recreación.

El Área Marina Costera Protegida Francisco Coloane (AMCP Francisco Coloane) ubicada en la porción nororiental del Estrecho de Magallanes, tiene como objetivo establecer una gestión ambiental integrada sobre la base de estudios e inventarios de sus recursos y una modalidad de conservación in situ de los ecosistemas y los hábitats naturales, a fin de alcanzar objetivos específicos de conservación (Decreto Supremo No276/2003, Ministerio de Defensa, Ministerio de
Economía). El AMCP Francisco Coloane contiene el primer Parque Marino de Chile de nombre homónimo y es aledaña a tres áreas destinadas para la conservación por el Ministerio de Bienes Nacionales y a la Reserva Nacional Alacalufes.

Son pocos los estudios sobre vegetación y de flora existentes en esta área protegida, entre ellos destacan los realizados por Pisano en 1970 en el estero Toro (53 $25^{\circ}$ S, $72^{\circ} 34^{\prime} \mathrm{W}$ ), Cóndor ( $53^{\circ} 19^{\prime} \mathrm{S}, 72^{\circ} 40^{\prime} \mathrm{W}$ ) y puerto Cutter Cove $\left(53^{\circ} 23^{\prime} \mathrm{S}, 72^{\circ} 26^{\prime} \mathrm{W}\right)$, donde describió las asociaciones vegetales: 1) herbácea litoral, 2) arbustiva litoral, 3) forestal de coigüe, 4) de ciprés, 5) turberas, 6) arbustiva montana y 7) herbáceas litoral. La riqueza de plantas vasculares halladas en los tres sitios asciende a 25 especies.

El objetivo del presente estudio es contribuir al conocimiento de la flora vascular que se encuentra en el AMCP Francisco Coloane mediante la confección de un catálogo pormenorizado de sus especies con información de su distribución, estado de conservación y usos.

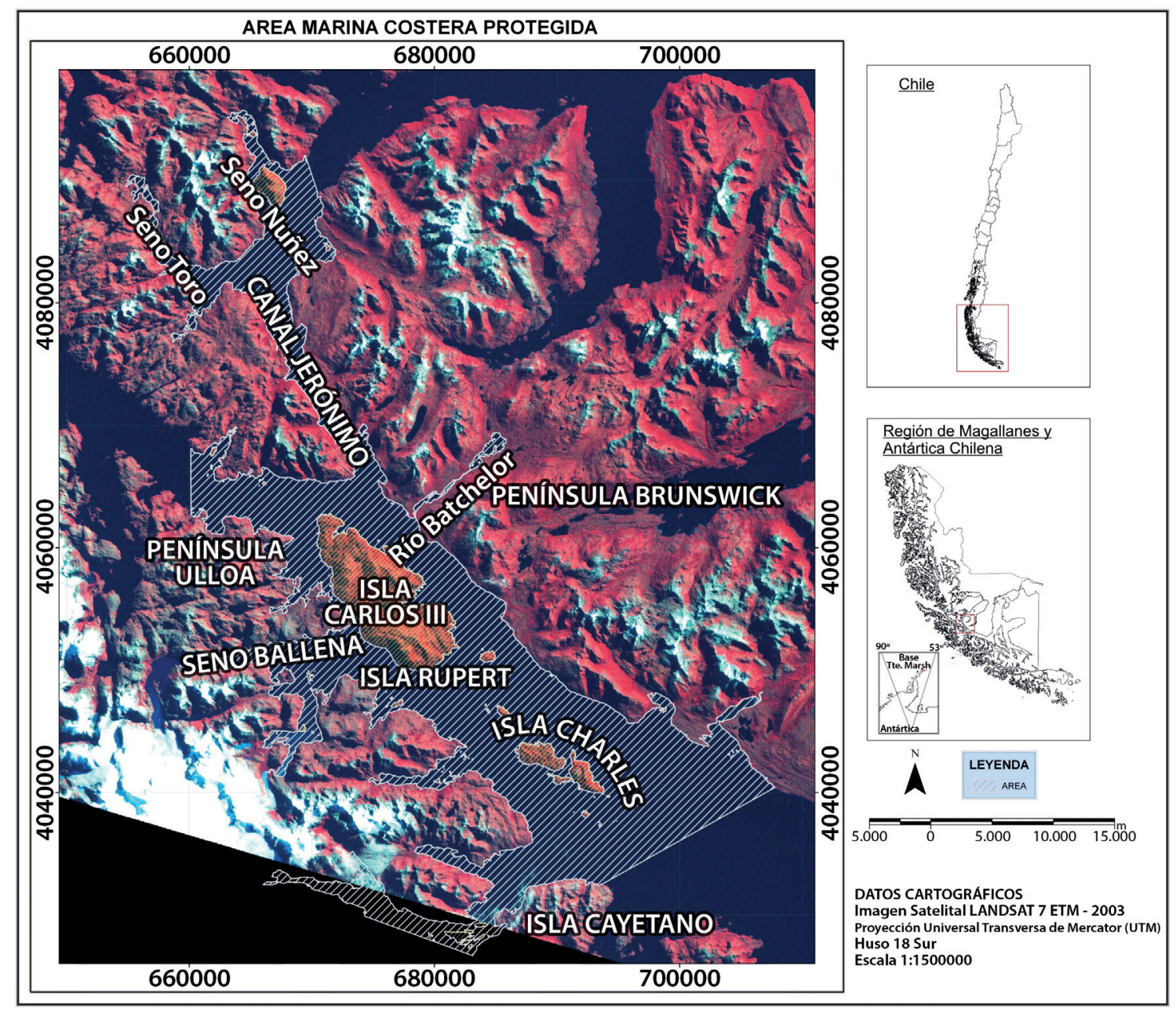

Figura 1. Localización geográfica del Área Marina Costera Protegida Francisco Coloane.

Figure 1. Geographical location of the Francisco Coloane Coastal Marine Protected Area. 
ÁREA DE ESTUDIO

El AMCP Francisco Coloane tiene una superficie de 67.000 hectáreas y presenta una elevada heterogeneidad ambiental dada por islas, islotes, fiordos, canales y una porción continental aledaña (Fig. 1). La geomorfología ha sido determinada por procesos de origen glaciar, destacando numerosos valles rodeados por cordones montañosos que no superan los 1.000 m s.n.m (Clapperton et al. 1995 Pisano 1970, 1973, Valle-Levinson et al. 2006). En general no existen extensiones planas, sólo un angosto y discontinuo borde costero (Pisano 1977, 1992).

La vegetación ha sido descrita por Pisano $(1977,1992)$ y Dollenz (1986), quienes distinguen el Bosque Magallánico siempreverde de Nothofagus betuloides, el Complejo de Tundra Magallánica y vegetación orofítica o altoandina correspondiente al área archipelágica. En el AMCP Francisco Coloane y en el área contigua hay un desarrollo incipiente de actividades económicas relacionadas con la pesca artesanal, la extracción de ciprés de las Guaytecas y la minería.

\section{MATERIALES Y MÉTODOS}

Se realizaron muestreos florísticos en primavera y verano entre los años 2006 y 2007, con el fin de maximizar el hallazgo de especies en estado reproductivo. En la Tabla I se indican los sitios seleccionados donde se realizaron los muestreos de la flora. En estas localidades se evaluó la riqueza de especies, a través de un total de 72 parcelas anidadas sensu Whittaker modificadas de $1.000 \mathrm{~m}^{2}$ y 720 subparcelas de $1 \mathrm{~m}^{2}$ (Stohlgren et al. 1999).

El material colectado fue identificado a nivel específico e infraespecífico a través del uso de floras y monografías (Correa 1969, 1971, 1978, 1984a, 1984b, 1988a, 1988b, 1998, Marticorena \& Quezada 1985, Moore 1983, Matthei 1995, Marticorena \& Rodríguez 1995, Zuloaga et al. 2011, Villagrán \& Barrera. 2002, Novoa et al. 2006). Para la determinación de la sinonimia y distribución de cada especie se utilizaron las bases de datos del Instituto de Botánica Darwinion (http://www2.darwin.edu.ar/) y Plant Names (http:/www.ipni.org/).

Los ejemplares identificados fueron clasificados según su origen geográfico (Matthei 1995, Henríquez et al. 1995, Espinoza 1996, Domínguez 2007) y estatus de invasión según lo propuesto por Pysek et al. (2004). Para analizar aspectos dinámicos de la vegetación se determinaron los tipos biológicos propuestos por Raunkiaer (1934) y modificadas por Mueller-Dombois \& Ellemberg (1974), los usos de las plantas dados por la etnia kawésqar (Domínguez 2010), y se identificaron las especies con problemas de conservación de acuerdo con su categoría (Benoit 1989, Baeza et al. 1998, Rodríguez et al. 2008, Rodríguez et al. 2009). Las plantas citadas en este estudio se encuentran depositadas en los herbarios CONC (Herbario de la Universidad de Concepción), HIP (Herbario del Instituto de la Patagonia) y un set de duplicados en la Secretaría Regional Ministerial de Bienes Nacionales de la Región de Magallanes.

TABLA I. Ubicación geográfica de los sitios de colecta en el AMCP Francisco Coloane, Región de Magallanes, Chile.

TABLE I. Location of collection sites in the AMCP Francisco Coloane, Magallanes, Chile.

\begin{tabular}{|c|c|}
\hline Sitios & CoOrdenadas \\
\hline Río Batchelor & $53^{\circ} 31^{\prime} 56,62^{\prime \prime} \mathrm{S}, 72^{\circ} 17^{\prime} 59,599^{\prime \prime O}$ \\
\hline Bahía Tres Islas & $53^{\circ} 29^{\prime} 3,35^{\prime \prime} \mathrm{S}, 72^{\circ} 22^{\prime} 41,50^{\prime \prime} \mathrm{O}$ \\
\hline Puerto Cutter Cove & $53^{\circ} 22^{\prime} 25,14^{\prime \prime} \mathrm{S}, 72^{\circ} 26^{\prime} 56,47^{\prime \prime} \mathrm{O}$ \\
\hline Bahía Mussel & $53^{\circ} 37^{\prime} 33,50^{\prime \prime} \mathrm{S}, 7^{\circ} 19^{\prime} 15,18^{\prime \prime} \mathrm{O}$ \\
\hline Bahía Tilly & $53^{\circ} 34^{\prime} 42,56^{\prime \prime} \mathrm{S}, 72^{\circ} 24^{\prime} 17,87^{\prime \prime} \mathrm{O}$ \\
\hline Seno Dean & $53^{\circ} 49^{\prime} 00^{\prime \prime} \mathrm{S}, 72^{\circ} 19^{\prime} 10^{\prime \prime} \mathrm{O}$ \\
\hline Estero Cóndor & $53^{\circ} 20^{\prime} 29,82^{\prime \prime} \mathrm{S}, 72^{\circ} 38^{\prime} 10,09^{\prime \prime O}$ \\
\hline Estero Toro & $53^{\circ} 26^{\prime} 1,69^{\prime \prime}$ S., 72॰34’29,29”O \\
\hline Isla Rupert & $53^{\circ} 39^{\prime} 43,75^{\prime \prime}$ S., $72^{\circ} 12^{\prime} 59,88^{\prime \prime O}$ \\
\hline Isla Monmouth & $53^{\circ} 42^{\prime} 00^{\prime \prime S} ., 72^{\circ} 11^{\prime} 03^{\prime \prime O}$ \\
\hline Isla Jaime Grande & $53^{\circ} 41^{\prime} 44,13^{\prime \prime S} ., 72^{\circ} 16,13^{\prime \prime O}$ \\
\hline Isla Jaime Chica & $53^{\circ} 41^{\prime} 44,91$ 'S., $72^{\circ} 12^{\prime} 51,52^{\prime \prime O}$ \\
\hline
\end{tabular}




\section{RESULTADOS}

Catálogo Florístico Comentado

\section{PTERIDOPHYTA}

\section{FILICOPSIDA}

\section{Asplenium dareoides Desv.}

Hierba perenne, epífita. Endémica de Argentina y Chile. En Chile se distribuye entre las regiones de Coquimbo y de Magallanes. Escasa, crece en los bosques de Nothofagus betuloides. Exs.: isla Rupert, isla Monmouth, río Batchelor. E. Domínguez 736, 868, 885 (CONC) 645 (HIP).

\section{Blechnaceae}

\section{Blechnum magellanicum (Desv.) Mett.}

Hierba perenne. Habita en Argentina, Islas Malvinas y Chile. En Chile se distribuye entre las regiones del Maule y de Magallanes. También ha sido reportada en el Archipiélago de Juan Fernández. Abundante, crece en los claros del bosque de Nothofagus betuloides. Exs.: Isla Riesco, Estero Toro; isla Santa Inés, bahía Dean, isla Rupert, isla Carlos III, bahía Tilly, península de Brunswick, río Batchelor. E. Domínguez 657, 689, 745, 821, 887, 888 (CONC) 647 (HIP).

\section{Blechnum penna-marina (Poiret) Kuhn}

Hierba perenne. Habita en Australia, islas de los océanos Pacífico, Atlántico sur e Índico en Brasil, Bolivia, Argentina y Chile. En Chile se distribuye entre las regiones de la Araucanía y de Magallanes. Frecuente, crece como sotobosque de Nothofagus betuloides. Exs.: isla Riesco, estero Cóndor, isla Carlos III, bahía Mussel, península de Brunswick, río Batchelor. E. Domínguez 675, 846, 927 (CONC); Carlos III, bahía Tilly 651 (HIP).

\section{Gleicheniaceae}

\section{Sticherus quadripartitus (Poir.) Ching}

Hierba perenne. Endémica de Argentina y Chile. En Chile se distribuye entre las regiones de Bío-Bío y de Magallanes, también ha sido reportada en el Archipiélago de Juan Fernández. Frecuente, crece en los claros del bosque y en los bordes de las turberas de Sphagnum. Exs.: isla Riesco, esteros Toro y Cóndor; isla Santa Inés, bahía Dean; isla Rupert; península de Brunswick, bahía Tres Islas; Isla Carlos III, bahías Tilly y Mussel. E. Domínguez 659, 676, 707, 746, 785, 806, 813, 847 (CONC); isla Riesco, estero Cóndor; isla Carlos III, bahía Mussel 648, 683 (HIP).

GRAMMITIDACEAE

5. Grammitis magellanica Desv.

Hierba perenne, epífita. Habita en Nueva Zelandia, Tristan da Cunha, Sudáfrica, Argentina Islas Malvinas y Chile. En Chile se distribuye entre las regiones de la Araucanía y de Magallanes, incluyendo también el Archipiélago de Juan Fernández. Escasa, crece sobre troncos de Nothofagus betuloides. Estado de conservación: Vulnerable (Baeza et al. 1998, Rodríguez et al. 2008, Rodríguez et al. 2009). Exs.: isla Santa Inés, bahía Dean; isla Carlos III, bahía Mussel; península de Brunswick, sector río Batchelor. E. Domínguez 705, 854, 884 (CONC).

6. Grammitis poeppigiana (Mett.) Pic.Serm. Hierba perenne, epífita. Habita en Nueva Zelandia, Tristan da Cunha, Sudáfrica Argentina y Chile. En Chile se distribuye entre las regiones de Bío-Bío y de Magallanes. Escasa, crece en sitios sombríos en grietas. Estado de conservación: Insuficientemente conocida (Baeza et al. 1998) y Vulnerable (Rodríguez et al. 2009). Exs.: península de Brunswick, sector río Batchelor. E. Domínguez 929 (CONC).

\section{HyMENOPHYLLACEAE}

\section{Hymenophyllum ferrugineum Colla}

Hierba perenne, epífita. Habita en Nueva Zelandia, Argentina y Chile. En Chile se distribuye entre las regiones de Los Ríos y de Magallanes, también ha sido reportada en el Archipiélago de Juan Fernández. Frecuente, crece bajo el dosel en el bosque costero de Nothofagus betuloides. Exs.: isla Carlos III, Bahía Mussel. E. Domínguez 862 (CONC).

\section{Hymenophyllum secundum Hook. et Grev.}

Hierba perenne, epífita. Endémica de Argentina y Chile. Se distribuye en Chile entre las regiones de Los Lagos y de Magallanes, también ha sido reportada en el Archipiélago de Juan Fernández. Abundante, crece bajo el dosel en el bosque de Nothofagus betuloides. Estado de conservación: Vulnerable (Baeza et al. 1998, Rodríguez et al. 2008, Rodríguez et al. 2009). Exs.: isla Riesco, estero Cóndor; isla Santa Inés, bahía Dean; península de Brunswick, bahía Tres Islas; isla Carlos III, bahía Tilly y Mussel, península de Brunswick, río Batchelor. E. Domínguez 686, 712, 775, $815,853,858,881,883$ (CONC).

\section{Hymenophyllum tortuosum Hook. et Grev.}

Hierba perenne, epífita. Endémica de Argentina y Chile. Se distribuye en Chile entre las regiones de Los Lagos y de Magallanes, también ha sido reportada en el Archipiélago de Juan Fernández. Frecuente, crece en el interior del bosque de Nothofagus betuloides. Estado de conservación: Vulnerable (Baeza et al. 1998, Rodríguez et al. 2008, Rodríguez et al. 2009). Exs.: isla Riesco, estero Cóndor; isla Rupert; isla Carlos III, bahía Mussel, península de Brunswick, río Batchelor. E. Domínguez 674, 687, 740, 841, 855, 928 (CONC). 
10. Serpyllopsis caespitosa (Gaudich.) C.Chr. Hierba perenne, epífita. Endémica de Argentina y Chile. En Chile se distribuye entre las regiones de Los Ríos y de Magallanes. Abundante, crece en la base de los troncos de Nothofagus betuloides. Estado de conservación: Insuficientemente conocida (Baeza et al. 1998, Rodríguez et al. 2008, Rodríguez et al. 2009). Exs.: isla Rupert, península de Brunswick río Batchelor. E. Domínguez 747, 922, 957 (CONC); 650 (HIP).

\section{Schizaea fistulosa Labill.}

\section{SCHIZEACEAE}

Hierba perenne. Habita en Australia, Nueva Zelandia, Nueva Caledonia, Malasia, Islas Malvinas, Argentina y Chile. En Chile se distribuye entre las regiones de Los Lagos y de Magallanes. Escasa, crece en turberas de plantas pulvinadas. Estado de conservación: Vulnerable (Baeza et al. 1998, Rodríguez et al. 2008, Rodríguez et al. 2009). Exs.: isla Riesco, estero Toro. E. Domínguez 656 (CONC); isla Riesco, estero Cóndor 657 (HIP).

\section{LYCOPSIDA}

\section{LYCOPODIACEAE}

\section{Huperzia fuegiana (Roiv.) Holub}

Hierba perenne. Endémica de Argentina, Islas Malvinas y Chile. En Chile se distribuye entre las regiones de Aysén y de Magallanes. Escasa, crece en ambiente altoandino. Estado de conservación: Rara (Baeza et al. 1998). Exs.: península de Brunswick, río Batchelor. E. Domínguez 894 (CONC); 654 (HIP) y Herbario Bienes Nacionales.

\section{Lycopodium confertum Willd.}

Hierba perenne. Endémica de Argentina, Islas Malvinas y Chile. En Chile se distribuye entre las regiones de Los Lagos y de Magallanes. Escasa, crece en ambiente altoandino. Estado de conservación: Rara (Baeza et al. 1998). Exs.: península de Brunswick, río Batchelor. E. Domínguez 894 (CONC); 653 (HIP).

\section{Lycopodium magellanicum (P.Beauv.) Sw.}

Hierba perenne. Habita en Venezuela, Ecuador, Perú, Argentina, Islas Malvinas, Hispaniola, Costa Rica y Chile. En Chile se encuentra entre las regiones de Bío-Bío y de Magallanes, también ha sido reportada en el Archipiélago de Juan Fernández. Frecuente, en zonas intermedias entre el bosque de Nothofagus betuloides y turberas de plantas pulvinadas. Exs.: bahía Tres Islas, península de Brunswick. E. Domínguez 652 (HIP).

\section{GYMNOSPERMAE}

\section{PINOPSIDA}

\section{CUPRESSACEAE}

\section{Pilgerodendron uviferum (D.Don) Florin}

Árbol siempreverde. Endémico de Argentina y Chile. Se distribuye en Chile entre las regiones de Los Lagos y de Magallanes. Frecuente, crece en la transición entre turberas y el bosque siempreverde. Estado de conservación: Vulnerable (Walters \& Guillett 1998, Rodríguez et al. 2008). Exs.: isla Riesco, estero Toro; isla Riesco, estero Cóndor; isla Santa Inés, bahía Dean; península de Brunswick, bahía Tres Islas; península de Brunswick, río Batchelor. E. Domínguez 667, 677, 692, 714, 784, 882, 890 (CONC); Isla Carlos III, bahía Tilly 658 (HIP).

\section{MAGNOLIOPHYTA}

\section{MAGNOLIOPSIDA}

\section{Apium prostatum Labill.}

\section{APIACEAE}

Hierba perenne. Habita en Brasil, Uruguay, Argentina y Chile. En Chile se distribuye entre las regiones de Antofagasta y de Magallanes, incluyendo también el archipiélago de Juan Fernández e Isla de Pascua. Frecuente, forma parte del pastizal costero. Exs.: isla Santa Inés, bahía Dean; península de Brunswick, río Batchelor. E. Domínguez 721, 911 (CONC); Isla Carlos III. Bahía Mussel 659 (HIP).

\section{Bolax caespitosa Hombr. \& Jacq. ex Decne.}

Hierba o subarbusto perenne. Habita en Argentina, Isla Malvinas y Chile. En Chile se distribuye entre las regiones de Los Lagos y de Magallanes. Frecuente, crece en forma de cojines compactos sobre el límite arbóreo. Exs.: isla Santa Inés, bahía Dean; península de Brunswick, bahía Tres Islas; isla Carlos III, bahía Tilly; península de Brunswick, río Batchelor. E. Domínguez 706, 796, 808, 940 (CONC).

\section{Lilaeopsis macloviana (Gand.) A.W.Hill}

Hierba perenne. Habita en Bolivia, Argentina, Isla Malvinas y Chile. En Chile se distribuye entre las regiones de Tarapacá y de Magallanes. Escasa, crece en suelo arenoso en el borde costero. Exs.: península de Brunswick, río Batchelor. E. Domínguez 938 (CONC).

\section{Schizeilema ranunculus (d'Urv.) Domin}

Hierba perenne. Habita en Argentina, Isla Malvinas y Chile. En Chile se distribuye entre las regiones de Los Lagos y de Magallanes. Frecuente, crece en terrenos pantanosos en el borde del río Batchelor. Exs.: península de Brunswick, río Batchelor. E. Domínguez 932 (CONC). 


\section{Araliaceae}

20. Raukaua laetevirens (Gay) Frodin

Árbol siempreverde. Endémico de Argentina y Chile. Se distribuye entre las regiones del Maule y de Magallanes. Frecuente, crece en el bosque costero de Nothofagus betuloides. Exs.: península de Brunswick, bahía Tres Islas; isla Carlos III, bahía Mussel; península de Brunswick, río Batchelor. E. Domínguez 791, 801, 859, 875, 955, 956 (CONC), península de Brunswick, puerto Cutter Cove 663 (HIP).

\section{AsterACEAE}

21. Baccharis patagonica Hook. \& Arn.

Arbusto erguido siempreverde. Endémico de Argentina y Chile. En Chile se distribuye entre las regiones de BíoBío y de Magallanes, incluyendo el Archipiélago de Juan Fernández. Abundante, crece formando parte del matorral costero. Exs.: isla Riesco, estero Toro; isla Santa Inés, bahía Dean; isla Carlos III, bahía Tilly. E. Domínguez 665, 691, 809,825 (CONC).

\section{Chiliotrichum diffusum (G. Forst.) Kuntze}

Arbusto erguido siempreverde. Habita en Argentina, Islas Malvinas y Chile. En Chile se distribuye entre las regiones de O'Higgins y de Magallanes. Frecuente, crece formando parte del matorral costero. Exs.: isla Santa Inés, bahía Dean; isla Rupert; península de Brunswick, bahía Tres Islas; isla Carlos III, bahía Tilly; península de Brunswick, río Batchelor. E. Domínguez 699, 729, 741, 776, 822, 832, 945 (CONC), isla Rupert 666 (HIP).

\section{Gamochaeta monticola (Phil. ex Reiche) Cabrera}

Hierba anual. Habita en Argentina y Chile. En Chile se distribuye entre las regiones de Coquimbo y de Magallanes. Escasa, crece en el borde de caminos abandonados. Representa una nueva adición para la flora vascular de Magallanes. Su presencia en la mina Cutter Cove se puede deber a una introducción accidental de semillas que llegaron mezcladas con barro proveniente de mineros, turistas o pescadores a la zona. Exs.: puerto Cutter Cove. E. Domínguez 984 (CONC).

\section{Hypochaeris arenaria Gaudich.}

Hierba perenne. Endémica de Chile y Argentina. En Chile se distribuye entre las regiones de Valparaíso y de Magallanes. Frecuente, crece en los bordes de turberas de Sphagnum. Exs.: península de Brunswick, río Batchelor. E. Domínguez 898 (CONC).

\section{Lagenophora nudicaulis (Comm. ex Lam.) Dusén} Hierba perenne. Endémica de Argentina y Chile. En Chile se distribuye entre las regiones de O'Higgins y de Magallanes. Escasa, crece en el borde de cursos de agua. Exs.: península de Brunswick, río Batchelor. E. Domínguez 907 (CONC).

\section{Leptinella scariosa Cass.}

Hierba perenne. Habita en Argentina, Islas Malvinas y Chile. En Chile se distribuye entre las regiones de la Araucanía y de Magallanes. Frecuente, crece en el pastizal costero en suelo arenoso. Exs.: península de Brunswick, río Batchelor; isla Jaime e isla Monmouth. E. Domínguez 643 (Herbario Bienes Nacionales).

\section{Macrachaenium gracile Hook. f.}

Hierba perenne. Endémica de Argentina y Chile. En Chile se distribuye entre las regiones del Bío-Bío y de Magallanes. Frecuente, crece en el interior del bosque de Nothofagus betuloides. Exs.: península de Brunswick, río Batchelor. E. Domínguez 923 (CONC), isla Riesco, estero Cóndor 672 (HIP).

\section{Nassauvia magellanica J.F. Gmel}

Hierba perenne. Endémica de Argentina y Chile. En Chile se distribuye solo en la Región de Magallanes. Escasa, crece en ambiente rocoso expuesto con pedregal suelto. Exs.: península de Brunswick, río Batchelor. E. Domínguez 891 (CONC).

\section{Perezia lactucoides (Vahl) Less.}

Hierba perenne. Endémica de Chile y Argentina. En Chile se distribuyen entre las regiones de la Araucanía y de Magallanes. Frecuente, crece en sitios húmedos, como las turberas de Sphagnum y ciperáceas. Exs.: isla Riesco, estero Cóndor; isla Carlos III, bahía Mussel; península de Brunswick, río Batchelor. E. Domínguez 683, 848, 877 (CONC).

\section{Perezia magellanica (L. f.) Lag.}

Hierba perenne. Endémica de Argentina y Chile. En Chile se distribuye entre las regiones de Aysén y de Magallanes. Frecuente, crece en sitios húmedos entre grietas por sobre el límite arbóreo, en sitios expuestos. Exs.: isla Riesco, estero Toro; isla Santa Inés, bahía Dean; península de Brunswick, bahía Tres Islas; isla Carlos III, bahía Tilly; Isla Carlos III, bahía Mussel; península de Brunswick, río Batchelor y puerto Cutter Cove. E. Domínguez 662, 726, 732, 773, 811, 838, 901, 975 (CONC).

31. Senecio acanthifolius Hombr. et Jacquinot

Hierba perenne. Endémica de Argentina y Chile. Se distribuye entre las regiones de Los Lagos y de Magallanes. Abundante, crece en los faldeos de los cerros, siendo el principal recurso forrajero para el huemul (Hippocamelus bisulcus). Exs.: isla Santa Inés, bahía Dean; isla Rupert; península de Brunswick, bahía Tres Islas; isla Carlos III, bahía Tilly; isla Carlos III, bahía Mussel; península de Brunswick, río Batchelor. E. Domínguez 704, 749, 789, 790, 823, 845, 900, 950 (CONC), isla Monmouth 669 (HIP). 
32. Senecio darwinii Hook. \& Arn.

Hierba perenne. Endémica de Argentina y Chile. En Chile se distribuye entre las regiones de los Lagos y de Magallanes. Escasa, crece en ambiente rocoso expuesto con pedregal suelto. Exs.: península de Brunswick, río Batchelor. E. Domínguez 892 (CONC) y 676 Herbario Bienes Nacionales.

\section{Senecio smithii DC.}

Hierba perenne. Endémica de Argentina y Chile. En Chile se distribuye entre las regiones de la Araucanía y de Magallanes. Frecuente, crece en la desembocadura de ríos y zonas pantanosas. Los kawésqar la conocen con el nombre de lampaso (Aguilera \& Tonko 2011). Exs.: isla Rupert; península de Brunswick, río Batchelor. E. Domínguez 761, 949 (CONC).

34 Senecio trifurcatus (G.Forst.) Less.

Hierba perenne. Endémica de Argentina y Chile. En Chile se distribuye entre las regiones de la Araucanía y de Magallanes. Frecuente, crece en turberas con plantas pulvinadas y ciperáceas. Exs.: península de Brunswick, río Batchelor. E. Domínguez 908 (CONC), isla Santa Inés, bahía Dean 678 (HIP).

\section{Symphyotrichum vahlii (Gaudich.) G.L. Nesom}

Hierba perenne. Habita en Argentina, Isla Malvinas y Chile. En Chile se distribuye entre las regiones del Maule y de Magallanes. Frecuente, crece en lugares húmedos formando parte del pastizal costero. Exs: isla Santa Inés, bahía Dean; isla Rupert; península de Brunswick, río Batchelor. E. Domínguez 697, 727, 765, 931 (CONC).

\section{Berberis ilicifolia L.f.}

\section{BERBERIDACEAE}

Arbusto siempreverde. Endémico de Argentina y Chile. En Chile se distribuye entre las regiones de Los Lagos y de Magallanes. Frecuente, crece en el interior del bosque de Nothofagus betuloides. Exs.: isla Santa Inés, bahía Dean; isla Rupert; isla Carlos III, bahía Tilly; isla Carlos III bahía Mussel; península de Brunswick, río Batchelor. E. Domínguez 717, 757, 804, 851, 925 (CONC).

\section{Berberis microphylla G. Forst.}

Arbusto siempreverde. Endémico de Argentina y Chile. En Chile se distribuye entre las regiones de O'Higgins y de Magallanes. Frecuente, crece en el borde costero en sitios abiertos. Los kawésqar recolectaban y consumían los frutos. Exs.: península de Brunswick, río Batchelor. E. Domínguez 948 (CONC).

\section{Callitrichaceae}

38. Callitriche antarctica Engelm. ex Hegelm.

Hierba anual acuática. Endémica de Argentina y Chile. En
Chile se distribuye entre las regiones de la Araucanía y de Magallanes. Escasa, crece arraigada en el borde de cursos de agua. Exs.: isla Monmouth. E. Domínguez 871 (CONC), isla Jaime Chica 681 (HIP).

\section{CARYOPHYLLACEAE}

39. Cerastium fontanum Baumg. ssp. vulgare (Hartmann) Greuter \& Burdel

Hierba anual. Introducida en Chile, originaria de Europa. En Chile se distribuye entre las regiones de Atacama y de Magallanes, también en el Archipiélago de Juan Fernández. Frecuente, crece en el borde de caminos abiertos por la minería de cobre establecida en el año 1906. Exs.: puerto Cutter Cove. E. Domínguez 995 (CONC).

40. Colobanthus quitensis (Kunth) Bartling

Hierba perenne. Habita en Colombia, Ecuador, Argentina, Islas Malvinas y Chile. Se distribuye en todo Chile, incluyendo la península antártica. Frecuente, crece en el borde costero, formando pequeños cojines. Exs.: isla Rupert. E. Domínguez 759 (CONC).

\section{Stellaria debilis d'Urv.}

Hierba perenne. Habita en Ecuador, Chile y Argentina. En Chile se distribuye entre las regiones de Coquimbo y de Magallanes. Frecuente, crece en el borde costero. Exs.: puerto Cutter Cove. E. Domínguez 981 (CONC).

\section{CElastraceaE}

42. Maytenus magellanica (Lam.) Hook.f.

Árbol siempreverde. Endémico de Argentina y Chile. En Chile se distribuye entre las regiones del Maule y de Magallanes. Frecuente, crece formando parte de los bosques costeros de Nothofagus betuloides. Exs.: isla Santa Inés, bahía Dean; isla Rupert; isla Monmouth; península de Brunswick, río Batchelor. E. Domínguez 702, 735, 873, 880, 952 (CONC).

\section{Crassula moschata G.Forst.}

Hierba anual. Habita en Argentina, Islas Malvinas y Chile. Se distribuye entre las regiones de los Lagos y de Magallanes. Frecuente, crece entre rocas en el borde costero. Exs.: isla Rupert; río Batchelor; puerto Cutter Cove. E. Domínguez 766, 769, 914, 976, 998 (CONC).

\section{DesfontAINIACEAE}

\section{Desfontainia fulgens D.Don}

Arbusto perenne. Habita en Bolivia, Argentina y Chile. En Chile se distribuye entre las regiones del Maule y de Magallanes. Abundante, crece en los claros del bosque siempreverde. Exs.: isla Riesco, estero Toro; isla Carlos III, bahía Tilly. E. Domínguez 664, 820, 826 (CONC). 


\section{DONATIACEAE}

45. Donatia fascicularis J.R. Forst. \& G. Forst.

Subarbusto perenne. Endémico de Argentina y Chile. En Chile se distribuye entre las regiones de Bío-Bío y Magallanes. Dominante en turberas de plantas pulvinadas junto a Astelia pumila, crece colonizando depresiones entre las rocas, en laderas de cerros. Exs.: isla Santa Inés, bahía Dean; península de Brunswick, bahía Tres Islas; isla Carlos III, bahía Tilly. E. Domínguez 711, 780, 834 (CONC), Isla Carlos III. Bahía Tilly 688 (HIP).

\section{Drosera uniflora Willd.}

\section{DroseraceAe}

Hierba perenne, insectívora, con pelos glandulares que le confieren un color rojizo. Habita en Argentina, Islas Malvinas y Chile. En Chile se distribuye entre las regiones de Bío-Bío y de Magallanes. Abundante, crece en las turberas con plantas pulvinadas y ciperáceas. Exs.: isla Riesco, estero Toro; isla Riesco, estero Cóndor; isla Santa Inés, bahía Dean; isla Carlos III, bahía Tilly; puerto Cutter Cove. E. Domínguez 666, 679, 716, 728, 824, 1003 (CONC).

\section{EMPETRACEAE}

47. Empetrum rubrum Vahl ex Willd.

Subarbusto bajo o rastrero. Habita en Argentina, Islas Malvinas y Chile. En Chile se distribuye entre las regiones de Valparaíso y de Magallanes, también ha sido reportado en el Archipiélago de Juan Fernández. Frecuente, crece sobre el límite del bosque y en turberas de Sphagnum. Exs.: isla Santa Inés, bahía Dean; isla Rupert; península de Brunswick, Tres Islas; isla Carlos III, bahía Tilly; isla Carlos III, bahía Mussel; península de Brunswick, río Batchelor. E. Domínguez 718, 733, 754, 799, 816, 836, 876 (CONC).

\section{EPACRIDACEAE}

\section{Lebetanthus myrsinites (Lam.) Dusén}

Subarbusto trepador. Endémico de Argentina y Chile. En Chile se distribuye entre las regiones de Los Lagos y de Magallanes. Frecuente, crece en los bosques siempreverdes de coigüe de Magallanes. Exs.: isla Carlos III, bahía Mussel. E. Domínguez 691 (HIP).

\section{ERICACEAE}

49. Gaultheria antarctica Hook.f.

Subarbusto siempreverde. Endémico de Argentina y Chile. En Chile se distribuye entre las regiones de la Araucanía y de Magallanes. Escaso, crece en turberas de plantas pulvinadas. Exs.: isla Carlos III, bahía Mussel. E. Domínguez 860 (CONC), isla Santa Inés, bahía Dean 692 (HIP) y Herbario Bienes Nacionales.

50. Gaultheria mucronata (L. f.) Hook. \& Arn. Subarbusto siempreverde. Endémico de Argentina y Chile.
En Chile se distribuye entre las regiones del Los Lagos y de Magallanes. Abundante, crece en el matorral costero. Exs.: isla Santa Inés, bahía Dean; isla Rupert; isla Carlos III, bahía Tilly; Isla Carlos III, bahía Mussel; isla Monmouth; península de Brunswick, río Batchelor. E. Domínguez 701, 739, 803, 861, 869, 924 (CONC), isla Rupert 693 (HIP).

\section{Gaultheria pumila (L. f.) D.J. Middleton}

Subarbusto siempreverde. Habita en Argentina, Islas Malvinas y Chile. En Chile se distribuye desde Aysén hasta Magallanes. Frecuente, crece sobre el límite del bosque en grietas y en el borde de cursos de agua. Los kawésqar recolectaban y consumían sus frutos. Exs.: península de Brunswick, bahía Tres Islas. E. Domínguez 782 (CONC).

\section{EsCALLONIACEAE}

\section{Escallonia serrata $\mathrm{Sm}$.}

Arbusto siempreverde. Endémico de Argentina y Chile. En Chile se distribuye entre las regiones de Los Lagos y de Magallanes. Frecuente, crece en límite arbóreo de Nothofagus antarctica. Exs.: isla riesco, estero Cóndor; isla Santa Inés, bahía Dean; isla Rupert; isla Carlos III, bahía Tilly; isla Carlos III, bahía Mussel; isla Monmouth; península de Brunswick, río Batchelor. E. Domínguez 672, 703, 762, 805, 837, 863, 902 (CONC).

\section{FABACEAE}

\section{Lupinus arboreus Sims}

Hierba perenne. Introducida en Chile, originaria de Norteamérica occidental. En Chile se distribuye entre las regiones de Coquimbo y de Magallanes. Escasa, presente sólo en la desembocadura del río Batchelor en sitios perturbados. Exs.: península de Brunswick, río Batchelor. E. Domínguez 944 (CONC) y 703 Herbario Bienes Nacionales.

\section{Ribes magellanicum Poiret}

Arbusto siempreverde. Endémico de Argentina y Chile. En Chile se distribuye entre las regiones de O'Higgins y de Magallanes. Frecuente, crece en los claros del bosque de Nothofagus betuloides. Los kawésqar recolectaban y consumían sus frutos. Exs.: península de Brunswick, puerto Cutter Cove y río Batchelor. E. Domínguez 601 Herbario Bienes Nacionales.

\section{GUNNERACEAE}

\section{Gunnera lobata Hook. f.}

Hierba perenne. Endémica de Argentina y Chile. En Chile se distribuye entre las regiones de Los Lagos y de Magallanes. Frecuente en turberas. Exs.: isla Riesco, estero Cóndor; isla Carlos III, bahía Tilly; isla Carlos III, bahía Mussel; península de Brunswick, río Batchelor. E. Domínguez 685, 827, 844, 930 (CONC). 
56. Gunnera magellanica Lam.

Hierba perenne. Habita en Colombia, Ecuador, Perú, Bolivia, Argentina, Islas Malvinas y Chile. En Chile se distribuye entre las regiones Metropolitana y de Magallanes. Frecuente, crece en claros en el bosque de coigüe y en el suelo arenoso del borde de los cuerpos de agua. Exs.: isla Rupert; puerto Cutter Cove. E. Domínguez 751, 1017 (CONC).

\section{LENTIBULARIACEAE}

\section{Pinguicula antarctica Vahl}

Hierba perenne. Endémica de Argentina y Chile. En Chile se distribuye entre las regiones de la Araucanía y de Magallanes. Frecuente, crece generalmente en paredes rocosas con escurrimiento de agua. Exs.: isla Riesco, estero Toro; isla Riesco, estero Cóndor; río Batchelor. E. Domínguez 663, 684, 909 (CONC).

\section{MisODENDRACEAE}

58. Misodendrum brachystachium DC.

Planta hemiparásita. Endémica de Argentina y Chile. En Chile se distribuye entre las regiones del Maule y de Magallanes. Escasa, su hospedero en el área es Nothofagus betuloides. Exs.: península de Brunswick, bahía Tres Islas. E. Domínguez 794, 800 (CONC).

59. Misodendrum punctulatum Banks ex DC. Planta hemiparásita. Endémica de Argentina y Chile. En Chile se distribuye entre las regiones del Maule y de Magallanes. Frecuente, su hospedero es Nothofagus antarctica. Exs.: isla Rupert; isla Carlos III, bahía Mussel. E. Domínguez 763, 840 (CONC).

\section{MyRTACEAE}

\section{Myrteola nummularia (Poir.) O. Berg}

Subarbusto rastrero. Habita en Bolivia, Argentina, Islas Malvinas y Chile. En Chile se distribuye entre las regiones de Bío-Bío y de Magallanes. Frecuente, crece en las turberas con plantas pulvinadas y en las de Sphagnum. Se caracteriza por su fragancia. Los kawésqar recolectaban y comían sus frutos. Exs.: isla Santa Inés, bahía Dean; isla Rupert; isla Carlos III, bahía Tilly; isla Carlos III, bahía Mussel; península de Brunswick, río Batchelor. E. Domínguez 694, 758, 807, 839, 857, 954 (CONC).

\section{NothofagaceAe}

61. Nothofagus antarctica (G. Forst.) Oerst.

Árbol caducifolio. Endémico de Argentina y Chile. En Chile se distribuye entre las regiones del Maule y de Magallanes. Frecuente, crece en el borde de turberas de Sphagnum y en el límite arbóreo. Exs.: isla Riesco, estero Cóndor; isla Santa Inés, bahía Dean; península de Brunswick, bahía Tres Islas, río Batchelor. E. Domínguez 678, 713, 792, 903, 933, 964 (CONC), península de Brunswick, río Batchelor, cerror Tres Picos 694 (HIP).
62. Nothofagus betuloides (Mirb.) Oerst.

Árbol siempreverde. Endémico de Argentina y Chile. En Chile se distribuye entre las regiones de Los Lagos y de Magallanes. Dominante en los bosques siempreverdes costeros. Los kawésqar usaban su madera para construir arpones. Exs.: isla Riesco, estero Toro; isla Riesco, estero Cóndor; isla Santa Inés, bahía Dean; Isla Rupert; península de Brunswick , bahía Tres Islas; isla Carlos III, bahía Tilly; isla Carlos III, bahía Mussel. E. Domínguez 660, 668, 719, 720, 731, 760, 777, 814, 843, 852 (CONC).

\section{ONAGRACEAE}

\section{Fuchsia magellanica Lam.}

Arbusto. Habita en Bolivia, Argentina y Chile. En Chile se distribuye entre las regiones de Valparaíso y de Magallanes. Frecuente, crece en el matorral costero, se caracteriza por ser un importante recurso alimenticio para el picaflor. Exs.: isla Rupert; península de Brunswick, bahía Tres Islas; isla Monmouth; puerto Cutter Cove. E. Domínguez 753, 793, 867, 872, 874, 973 (CONC).

\section{Plantaginaceae}

\section{Hebe elliptica (G. Forst.) Pennell}

Subarbusto perenne. Endémico de Argentina y Chile. En Chile se distribuye entre las regiones de Aysén y de Magallanes. Frecuente, crece en el borde costero. Exs.: isla Rupert; isla Monmouth; península de Brunswick, río Batchelor. E. Domínguez 750, 864, 870, 946 (CONC), islote Jaime Chica 721 (HIP).

\section{Plantago barbata G. Forst.}

Hierba perenne. Endémica de Chile y Argentina. En Chile se distribuye entre las regiones de Atacama y de Magallanes. Frecuente, crece en el pastizal costero. Exs.: península de Brunswick, bahía Tres Islas, río Batchelor y puerto Cutter Cove.; isla Monmouth.

\section{Plumbaginaceae}

66. Armeria maritima (Mill.) Willd.

Hierba perenne. Habita en Canadá, Groenlandia, Estados Unidos, Argentina y Chile. En Chile se distribuye entre las regiones de Coquimbo y de Magallanes. Frecuente en el borde costero, crece sobre suelo pedregoso. Exs.: península de Brunswick, río Batchelor. E. Domínguez 971 (CONC).

\section{Rumex crispus L.}

\section{Polygonaceae}

Hierba perenne, introducida en Chile. Originaria de Europa. En Chile se distribuye entre las regiones de Atacama y de Magallanes. Frecuente en el borde costero, crece en sitios perturbados. Exs.: península de Brunswick, río Batchelor. E. Domínguez 706 (HIP). 


\section{Proteaceae}

68. Embothrium coccineum J.R. Forst. \& G. Forst.

Árbol o arbusto siempreverde. Endémica de Argentina y Chile. En Chile se distribuye entre las regiones del Maule y de Magallanes. Escaso, crece en sitios expuestos en laderas rocosas. Exs.: isla Santa Inés, bahía Dean. E. Domínguez 725 (CONC).

\section{RanunCUlaceae}

69. Caltha appendiculata Pers.

Hierba perenne. Endémica de Argentina y Chile. En Chile se distribuye entre las regiones del Libertador Bernardo O’Higgins y de Magallanes. Abundante, crece en turberas de Sphagnum. Exs.: isla Riesco, estero Cóndor; península de Brunswick, bahía Tres Islas. E. Domínguez 680 (CONC), 708 (HIP).

\section{Caltha dioneifolia Hook.f.}

Hierba perenne. Endémica de Argentina y Chile. En Chile se distribuye entre las regiones de Aysén y de Magallanes. Frecuente en turberas de plantas pulvinadas en las laderas de cerros. Exs.: isla Santa Inés, bahía Dean; península de Brunswick, bahía Tres Islas; isla Carlos III, bahía Tilly. E. Domínguez 722, 783, 818 (CONC).

71. Halerpestes uniflora (Phil. ex Reiche) Emadzade, Lehnebach, P. Lockh. \& Hörandl

Hierba perenne. Endémica de Argentina y Chile. En Chile se distribuye entre las regiones de Tarapacá y de Magallanes. Escasa, crece en el borde de cuerpos de agua. Exs.: puerto Cutter Cove. E. Domínguez 979 (CONC).

\section{Rosaceae}

\section{Acaena antarctica Hook.f.}

Hierba perenne. Endémica de Argentina y Chile. En Chile se distribuye entre las regiones de la Araucanía y de Magallanes. Escasa, crece formando parte de la vegetación altoandina. Exs.: península de Brunswick, bahía Tres Islas. E. Domínguez 797 (CONC).

\section{Acaena ovalifolia Ruiz et Pav.}

Hierba perenne. Habita en Argentina, Islas Malvinas y Chile. En Chile se distribuye entre las regiones del Maule y de Magallanes. Frecuente, crece en los pastizales costeros. Exs.: península de Brunswick, río Batchelor. E. Domínguez 917, 969 (CONC).

\section{Acaena pumila Vahl}

Hierba perenne. Endémica de Argentina y Chile. En Chile se distribuye entre las regiones de Los Lagos y de Magallanes. Frecuente, crece en turberas con plantas pulvinadas o con Sphagnum. Exs.: isla Riesco, estero Cóndor; península de Brunswick, río Batchelor; puerto Cutter Cove. E. Domínguez 669, 936, 962, 963, 1002 (CONC), isla Carlos
III, bahía Mussel 713 (HIP).

\section{Geum involucratum Pers.}

Hierba perenne. Endémica de Argentina y Chile. En Chile se distribuye entre las regiones de Los Lagos y de Magallanes. Escasa, crece en el pastizal costero. Exs.: Sector Tres Islas.

\section{Rubiaceae}

76. Galium aparine L.

Hierba anual. Introducida en Chile, originaria de Europa. Se encuentra entre las regiones de Tarapacá y de Magallanes. Frecuente, crece en sitios sombríos en el matorral costero. Exs.: península de Brunswick, río Batchelor. E. Domínguez 915 (CONC).

\section{SANTALACEAE}

77. Nanodea muscosa Banks ex C.F. Gaertn.

Hierba perenne. Endémica de Argentina y Chile. En Chile se distribuye entre las regiones de Los Lagos y de Magallanes. Frecuente, crece en turberas de Sphagnum. Exs.: isla Rupert; isla Carlos III, bahía Mussel; isla Monmouth. E. Domínguez 748, 856, 865 (CONC).

\section{SAXIFRAGACEAE}

\section{Chrysosplenium macranthum Hook.}

Hierba perenne. Endémica de Argentina y Chile. En Chile se distribuye en la Región de Magallanes. Escasa, crece en el pastizal costero, sobre sustrato arenoso. Exs.: puerto Cutter Cove. E. Domínguez 989 (CONC).

\section{SCROPHULARIACEAE}

79. Ourisia breviflora Benth.

Hierba perenne. Endémica de Argentina y Chile. En Chile se distribuye entre las regiones de Aysén y de Magallanes. Escasa, crece sobre el límite arbóreo, entre grietas de rocas. Exs.: península de Brunswick, bahía Tres Islas, río Batchelor. E. Domínguez 787, 904, 965 (CONC).

\section{StylidiaceAe}

80. Phyllachne uliginosa J.R. Forst. \& G. Forst. Subarbusto. Endémica de Argentina y Chile. En Chile se distribuye entre las regiones de Aysén y de Magallanes. Frecuente, crece en las turberas de plantas pulvinadas y por sobre el límite arbóreo. Exs.: isla Santa Inés, bahía Dean; península de Brunswick, río Batchelor. E. Domínguez 709, 899 (CONC), península de Brunswick, cerro Tres Picos 722 (HIP).

\section{THYMELAEACEAE}

\section{Drapetes muscosus Lam.}

Hierba perenne. Endémica de Argentina y Chile. En Chile se distribuye entre las regiones de Aysén y de Magallanes. Frecuente, crece en las turberas de Sphagnum y formando parte de la vegetación altoandina que se encuentra sobre el 
límite del bosque de Nothofagus antarctica. Exs.: península de Brunswick, bahía Tres Islas, río Batchelor. E. Domínguez 795, 942 (CONC).

\section{Tribeles australis Phil.}

\section{Tribelaceae}

Subarbusto siempreverde. Endémico de Argentina y Chile. En Chile se distribuye entre las regiones de Los Lagos y de Magallanes. Frecuente, crece en turberas de plantas pulvinadas. Exs.: puerto Cutter Cove. E. Domínguez 1005, 1008 (CONC).

\section{Violaceae}

83. Viola commersonii DC. ex Ging.

Hierba perenne. Endémica de Argentina y Chile. En Chile se distribuye en la Región de Magallanes. Escasa, crece en los claros próximos al límite del bosque achaparrado de Nothofagus antarctica. Exs.: Sector Tres Islas. E. Domínguez 798 (CONC).

\section{Viola tridentata Menzies ex Ging.}

Hierba perenne. Endémica de Argentina y Chile. En Chile se distribuye entre las regiones de Los Lagos y de Magallanes. Escasa, crece sobre el límite del bosque, donde forma parches entre grietas, ubicadas en caídas de agua. Exs.: península de Brunswick, río Batchelor. E. Domínguez 895 (CONC).

\section{WinTERACEAE}

85. Drimys winteri J.R. Forst. \& G. Forst.

Árbol siempreverde. Endémica de Argentina y Chile. En Chile se distribuye entre las regiones de Coquimbo y de Magallanes. Frecuente, crece en el bosque costero de Nothofagus betuloides. Exs.: isla Santa Inés, bahía Dean; isla Rupert; isla Carlos III, bahía Tilly; península de Brunswick, río Batchelor. E. Domínguez 698, 730, 738, 831, 879, 951, 953, 959 (CONC), isla Rupert 726 (HIP).

\section{LILIOPSIDA}

\section{Asteliaceae}

86. Astelia pumila (G. Forst.) Gaudich.

Hierba perenne. Habita en Argentina, Islas Malvinas y Chile. Se distribuye entre las regiones del Maule y de Magallanes. Abundante, crece en turberas de plantas pulvinadas junto a Donatia fascicularis. Exs.: isla Santa Inés, bahía Dean; isla Rupert; península de Brunswick, bahía Tres Islas; isla Carlos III, bahía Tilly. E. Domínguez 723, 752, 778, 819 (CONC).

\section{Centrolepidaceae}

87. Gaimardia australis Gaudich.

Hierba perenne. Endémica de Argentina y Chile. En Chile se distribuye entre las regiones de Los Lagos y de Magallanes.
Frecuente, crece en turberas de plantas pulvinadas. Exs.: isla Santa Inés, bahía Dean; península de Brunswick, bahía Tres Islas; isla Carlos III, bahía Tilly. E. Domínguez 724, 771, 810, 833 (CONC).

\section{Carex andersonii Boott}

\section{Cyperaceae}

Hierba perenne. Endémica de Argentina y Chile. En Chile se distribuye entre las regiones de la Araucanía y de Magallanes. Frecuente, crece en sitios anegados y en el borde de los esteros. Exs.: puerto Cutter Cove. E. Domínguez 978, 1016, 1019 (CONC).

\section{Carex darwinii Boott}

Hierba perenne. Habita en Nueva Zelandia, Argentina y Chile. En Chile se distribuye entre las regiones de la Araucanía y de Magallanes. Frecuente, crece en los humedales. Exs.: península de Brunswick, río Batchelor. E. Domínguez 913 (CONC).

\section{Carex kingii (Boott) Reznicek}

Hierba perenne. Endémica de Argentina y Chile. En Chile se distribuye entre las regiones de Aysén y de Magallanes. Escasa, formando parte de la vegetación altoandina que se encuentra entre los 600 a 1000 m.s.n.m. Exs.: península de Brunswick, Tres Islas, río Batchelor. E. Domínguez 788, 906 (CONC) y 730 Herbario Bienes Nacionales.

\section{Carex magellanica Lam.}

Hierba perenne. Habita en Argentina, Isla Malvinas y Chile. En Chile se distribuye entre las regiones de O'Higgins y de Magallanes. Frecuente, crece en el borde de lagunillas y en turberas de Sphagnum. Exs.: península de Brunswick, río Batchelor. E. Domínguez 934, 967 (CONC).

\section{Carex microglochin Wahlenb.}

Hierba perenne. Habita en Bolivia, Argentina y Chile. En Chile se distribuye entre las regiones de Coquimbo y de Magallanes. Frecuente, crece en el bosque y en las turberas de Sphagnum. Exs.: isla Carlos III, bahía Mussel; península de Brunswick, río Batchelor, puerto Cutter Cove. E. Domínguez 850, 960, 1001 (CONC).

\section{Carpha schoenoides Banks \& Sol. ex Hook. f.}

Hierba perenne. Endémica de Argentina y Chile. En Chile se distribuye entre las regiones de Aysén y de Magallanes. Abundante, crece en turberas de ciperáceas. Exs.: isla Santa Inés, bahía Dean; puerto Cutter Cove. E. Domínguez 695, 1004, 1007 (CONC), península de Brunswick, cerro Tres Picos, sector río Batchelor. 733 (HIP).

94. Isolepis cernua (Vahl) Roem. \& Schult.

Hierba anual. Habita en Australia, Nueva Zelandia y otras islas de Oceanía, Brasil, Uruguay, Argentina y Chile. En 
Chile se distribuye entre las regiones de Tarapacá y de Magallanes. Escasa, crece en el borde costero. Exs.: isla Rupert; puerto Cutter Cove. E. Domínguez 734, 996, 1014, 1021, 1023 (CONC).

95. Oreobolus obtusangulus Gaudich.

Hierba perenne. Habita en Argentina, Islas Malvinas y Chile. En Chile se distribuye entre las regiones de Bío-Bío y de Magallanes. Frecuente, crece en turberas con plantas pulvinadas junto a Donatia fascicularis. Exs.: isla Riesco, estero Toro; Isla Riesco, estero Cóndor; isla Santa Inés, bahía Dean; península de Brunswick, bahía Tres Islas; isla Carlos III, bahía Tilly; península de Brunswick, río Batchelor; puerto Cutter Cove. E. Domínguez 658, 673, 688, 715, 779, 829, 889, 977, 1022 (CONC).

96. Schoenus antarcticus (Hook. f.) Dusén

Hierba perenne. Endémica de Argentina y Chile. En Chile se distribuye entre las regiones de Aysén y de Magallanes. Abundante, crece en las turberas de ciperáceas. Exs.: isla Santa Inés, bahía Dean; isla Carlos III, bahía Tilly; península de Brunswick, río Batchelor, puerto Cutter Cove. E. Domínguez 696, 817, 943, 1006 (CONC), Río Batchelor 735 (HIP).

\section{Scirpus cernuus Vahl}

Hierba perenne. Habita en Argentina, Islas Malvinas y Chile. En Chile se distribuye entre las regiones de Aysén y de Magallanes. Escasa, crece en el borde costero. Exs.: península de Brunswick, río Batchelor. E. Domínguez 912 (CONC).

\section{Uncinia lechleriana Steud.}

Hierba perenne. Endémica de Argentina y Chile. En Chile se distribuye entre las regiones de Aysén y de Magallanes. Frecuente, crece en pantanos en el interior del bosque. Exs.: península de Brunswick, río Batchelor. E. Domínguez 921 (CONC).

\section{Uncinia tenuis Poepp. ex Kunth}

Hierba perenne. Habita en Colombia, Costa Rica, Ecuador, Honduras, Argentina, Islas Malvinas y Chile. En Chile se distribuye entre las regiones de la Araucanía y de Magallanes, también ha sido registrada en el Archipiélago Juan Fernández. Escasa, crece en el sotobosque de Nothofagus betuloides. Exs.: isla Carlos III, bahía Mussel; península de Brunswick, río Batchelor; puerto Cutter Cove. E. Domínguez 849, 920, 999 (CONC).

\section{IRIDACEAE}

\section{Tapeinia pumila (G.Forst.) Baillon}

Hierba perenne. Endémica de Argentina y Chile. En Chile se distribuye entre las regiones de la Araucanía y de Magallanes. Frecuente, crece en las turberas con plantas pulvinadas. Exs.: isla Riesco, estero Cóndor; isla Santa Inés, bahía Dean; península de Brunswick, bahía Tres Islas; isla Carlos III, bahía Tilly; puerto Cutter Cove. E. Domínguez 681, 693, 781, 828, 972 (CONC).

\section{JUNCACEAE}

101. Juncus scheuchzerioides Gaudich.

Hierba perenne. Habita en Nueva Zelandia, Argentina, Islas Malvinas y Chile. En Chile se distribuye entre las regiones de Atacama y de Magallanes. Frecuente, crece en los pantanos y en la orilla de esteros. Exs.: puerto Cutter Cove. E. Domínguez 983, 1012, 1020 (CONC).

\section{Marsippospermum grandiflorum (L.f.) Hook.}

Hierba perenne. Habita en Argentina, Islas Malvinas y Chile. En Chile se distribuye entre las regiones de BíoBío y de Magallanes. Frecuente, crece en las turberas con Sphagnum. Los kawésqar usan la fibra del tallo para fabricar cestas. Exs.: isla Rupert; isla Carlos III, bahía Mussel; península de Brunswick, río Batchelor; puerto Cutter Cove. E. Domínguez 767, 835, 937, 1000, 1009 (CONC).

\section{Rostkovia magellanica (Lam.) Hook.f.}

Hierba perenne. Habita en Argentina, Islas Malvinas y Chile. En Chile se distribuye entre las regiones de Los Lagos y de Magallanes. Frecuente, crece en las turberas de Sphagnum. Exs.: península de Brunswick, río Batchelor. E. Domínguez 893 (CONC).

\section{JUNCAGINACEAE}

\section{Tetroncium magellanicum Willd.}

Hierba perenne. Endémica de Argentina y Chile. En Chile se distribuye entre las regiones de la Araucanía y de Magallanes. Abundante, crece en las turberas de Sphagnum. Exs.: isla Riesco, estero Cóndor; isla Santa Inés, bahía Dean; península de Brunswick, río Batchelor; Puerto Cutter Cove. E. Domínguez 682, 700, 878, 1011 (CONC).

\section{ORCHIDACEAE}

105. Codonorchis lessonii (Brongn.) Lindl.

Hierba perenne. Habita en Argentina, Islas Malvinas y Chile. En Chile se distribuye entre las regiones del Maule y de Magallanes. Escasa, crece en el bosque achaparrado de Nothofagus antarctica por sobre los 350 m.s.n.m. Exs.: península de Brunwick, río Batchelor. E. Domínguez 970 (CONC).

\section{Philesiaceae}

106. Luzuriaga marginata (Gaertn.) Benth.

Subarbusto. Habita en Argentina, Islas Malvinas y Chile. En Chile se distribuye entre la Región de Los Lagos y de Magallanes. Frecuente, crece en los bordes del bosque de coigüe. Exs: isla Riesco, estero Cóndor; isla Rupert; isla Carlos III, bahía Tilly; península de Brunswick, río 
Batchelor. E. Domínguez 671, 755, 802, 926, 961 (CONC), puerto Cutter Cove 748 (HIP).

\section{Philesia magellanica J.F.Gmel.}

Subarbusto siempreverde, trepador con flores vistosas. Endémico de Argentina y Chile. Se distribuye entre las regiones de Los Lagos y de Magallanes. Frecuente, crece en los bosques costeros y en turberas. Exs.: isla Riesco, estero Toro; isla Santa Inés, bahía Dean; isla Rupert; península de Brunswick, bahía Tres Islas; isla Carlos III, bahía Tilly; isla Carlos III, bahía Mussel; península de Brunswick, río Batchelor, puerto Cutter Cove. E. Domínguez 661, 690, 756, 768, 774, 830, 842, 886, 947, 974 (CONC).

\section{POACEAE \\ 108. Agrostis magellanica Lam.}

Hierba perenne. Endémica de Argentina y Chile. En Chile se distribuye entre las regiones de la Araucanía y de Magallanes. Frecuente, crece en los claros del bosque costero. Exs.: puerto Cutter Cove. E. Domínguez 1010 (CONC).

\section{Agrostis meyenii Trin.}

Hierba perenne. Habita en Bolivia, Argentina y Chile. En Chile se distribuye entre las regiones de Coquimbo y de Magallanes. Frecuente, crece formando parte del pastizal costero. Exs.: puerto Cutter Cove. E. Domínguez 993 (CONC).

\section{Alopecurus magellanicus Lam.}

Hierba perenne. Habita en Bolivia, Argentina y Chile. En Chile se distribuye entre las regiones de Bío-Bío y de Magallanes. Abundante, crece formando parte del pastizal costero. Exs.: puerto Cutter Cove. E. Domínguez 986, 991 (CONC).

\section{Anthoxanthum redolens (Vahl) P. Royen}

Hierba perenne. Habita en Argentina, Islas Malvinas y Chile. En Chile se distribuye entre las regiones de Coquimbo y de Magallanes. Frecuente, crece formando parte del pastizal costero. Exs.: isla Riesco, estero Cóndor; isla Santa Inés, bahía Dean; isla Rupert; isla Carlos III, bahía Tilly; Isla Monmouth; península de Brunswick, río Batchelor, puerto Cutter Cove. E. Domínguez 670, 710, 737, 744, 770, 812, 866, 910, 987 (CONC), península de Brunswick, río Batchelor 753 (HIP).

\section{Deschampsia kingii (Hook.f.) E.Desv.}

Hierba perenne. Endémica de Argentina y Chile. En Chile se distribuye entre las regiones de Aysén y de Magallanes. Frecuente, crece formando parte del pastizal en el borde de ríos y cursos de agua. Exs.: península de Brunswick, río Batchelor; puerto Cutter Cove. E. Domínguez 939, 994 (CONC), río Batchelor 754 (HIP).
113. Elymus magellanicus (E. Desv.) A. Löve

Hierba perenne robusta. Endémica de Argentina y Chile. En Chile se distribuye solo en la Región de Magallanes. Escasa, crece formando parte del pastizal costero. Exs.: isla Santa Inés, bahía Dean; isla Rupert; península de Brunswick, río Batchelor; puerto Cutter Cove. E. Domínguez 708, 743, 919, 958, 992, 1018 (CONC).

\section{Festuca purpurascens Banks et Sol. ex Hook.f.}

Hierba perenne. Endémica de Argentina y Chile. En Chile se distribuye entre las regiones de Bío-Bío y de Magallanes. Escasa, crece formando parte del pastizal costero. Exs.: puerto Cutter Cove. E. Domínguez 980 (CONC).

\section{Holcus lanatus L.}

Hierba anual. Introducida en Chile, originaria de Europa. Habita en Brasil, Uruguay, Argentina y Chile. En Chile se distribuye entre las regiones de Coquimbo y de Magallanes. Planta forrajera. Frecuente, crece en sitios alterados. Exs.: península de Brunswick, río Batchelor. E. Domínguez 916 (CONC), río Batchelor 756 (HIP).

\section{Ortachne rariflora (Hook.f.) Hughes}

Hierba perenne. Endémica de Argentina y Chile. En Chile se distribuye entre las regiones de Los Lagos y de Magallanes. Frecuente, crece sobre el límite del bosque, forma parte de la vegetación altoandina. Exs.: península de Brunswick, río Batchelor. E. Domínguez 896, 941 (CONC), península de Brunswick, cerro Tres Picos 757 (HIP).

117. Poa alopecurus (Gaudich. ex Mirb.) Kunth Hierba perenne. Endémica de Chile y Argentina. En Chile se distribuye entre las regiones Metropolitana y de Magallanes. Frecuente, crece en el pastizal costero. Exs.: isla Rupert; península de Brunswick, río Batchelor; puerto Cutter Cove. E. Domínguez 742, 935, 968, 982, 1013 (CONC).

\section{Poa glauca Vahl}

Hierba perenne. Introducida en Chile y Argentina, originaria de Europa. Se encuentra sólo en la Región de Magallanes. Escasa, crece en el borde costero en sitios alterados. Exs.: isla Rupert; península de Brunswick, río Batchelor; puerto Cutter Cove. E. Domínguez 764, 918, 988 (CONC).

\section{Poa pratensis L. ssp. pratensis}

Hierba perenne. Introducida en Chile, Argentina, Brasil y Uruguay, originaria de Europa. En Chile se distribuye entre las regiones de Atacama y de Magallanes. Escasa, crece en el borde costero, en sitios alterados. Exs.: puerto Cutter Cove. E. Domínguez 997, 1015 (CONC).

120. Nicoraepoa robusta (Steud.) Soreng \& L.J. Gillespie Hierba perenne. Habita en Argentina, Islas Malvinas y Chile. En Chile se distribuye entre las regiones de Aysén 
y de Magallanes. Escasa, crece formando parte del pastizal costero. Exs.: puerto Cutter Cove. E. Domínguez 985, 990 (CONC).

\section{DISCUSIÓN}

El catálogo de la flora vascular del AMCP Francisco Coloane queda constituido por 120 especies, 92 géneros y 55 familias (Tabla II). De las cuales 69 son especies endémicas para Argentina y Chile, representando un 13\% de la biodiversidad de plantas vasculares citadas para la Región de Magallanes (Henríquez et al. 1995). Las familias más diversas son: Asteraceae (11 géneros/15 especies), Poaceae $(10 / 13)$ y Cyperaceae $(6 / 12)$. Los géneros que contienen más especies son: Carex (5 especies), Senecio (4) y 72 géneros representados por una especie. Dos especies representan nuevos registros para la flora vascular de la Región de Magallanes: Lupinus arboreus y Gamochaeta monticola.

Las especies introducidas halladas corresponden al $5 \%$ de la flora total, para una superficie de 67.000 ha, todas en categoría de naturalizadas (Tabla III). Una tendencia similar ha sido detectada en el Parque Nacional Cabo de Hornos, un ecosistema insular donde se registró un número aun menor de especies introducidas $(1,8 \%)$ (Rozzi et al. 2004). También podemos comparar los resultados del presente estudio con los consignados para la flora del Parque Nacional Pali Aike la que presenta un $10 \%$ de especies introducidas para una superficie de 5.030 ha (Domínguez et al. 2004). El bajo porcentaje de especies introducidas, confirma el buen estado de conservación de la vegetación, existiendo sólo evidencias de daños puntuales en la vegetación en la desembocadura del río Batchelor y en el borde costero de la mina abandonada de puerto Cutter Cove. Ambas localidades se encuentran en la zona continental y en ambas hay basura, escombros y residuos orgánicos depositados en el borde costero, lo cual ha dado origen al asentamiento de especies introducidas como: Lupinus arboreus que representa un nuevo registro para la flora de Magallanes. Otras especies encontradas en este tipo de ambiente fueron Holcus lanatus (pasto miel), Rumex crispus (romasa), Galium aparine (lengua de gato), lo que se ajusta a lo descrito por Ramírez et al. (1993). Las restantes especies introducidas como Poa pratensis y Cerastium fontanum fueron encontradas en puerto Cutter Cove. Las seis especies fueron clasificadas de acuerdo a su estatus de invasión como especies naturalizadas, entendiendo que ellas actualmente se reproducen en forma natural, y mantienen una población sin la intervención directa del hombre (Tabla III).

La distribución porcentual de las formas de vida de Raunkiaer (Tabla IV) muestra que los mejores representados dentro de la flora del AMCP Francisco Coloane son las hemicriptófitas que agrupan a las hierbas perennes no gramíneas y graminoides. Entre las hierbas adquiere importancia Senecio acanthifolius por ser el alimento principal para el Hippocamelus bisulcus (huemul) en sectores andinos en el río Batchelor y bahía Tres Islas. Entre los graminoides destacan Schoenus antarcticus y Carpha schoenoides por ser especies importantes en términos de cobertura y frecuencia en turberas de ciperáceas. Por una parte, las gramíneas Poa alopecurus y Deschampsia kingii son importantes en pastizales costeros formando densos conglomerados, que son utilizados como sitio de anidación por la avifauna local. Entre los arbustos destaca: Fuchsia magellanica por ser un importante recurso alimenticio para el Sephanoides galeritus (picaflor). Entre los subarbustos, destaca en términos de cobertura y frecuencia Empetrum rubrum en turberas de Sphagnum. Los árboles se encuentran representados por seis especies (5\%): Pilgerodendron uviferum, Drimys winteri, Maytenus magellanica, Raukaua laetevirens, Nothofagus antarctica y Nothofagus betuloides, siendo esta última la principal especie estructuradora de hábitat y principal refugio para la fauna en el área de estudio. Las hierbas o arbustos enanos pulvinados o en cojín son importantes en las turberas que se encuentran por sobre el límite arbóreo, formando parte de la vegetación andina. Los helechos epífitos se encuentran representados por tres especies: Grammitis magellanica, Grammitis poeppigiana y Serpyllopsis caespitosa. Las plantas hemiparásitas leñosasestán representadas por: Misodendrum punctulatum y Misodendrum brachystachium. Las plantas anuales están representadas por Holcus lanatus y Galium aparine, ambas introducidas en Chile, de origen europeo (Domínguez et al. 2006) (Tabla IV).

El AMCP Francisco Coloane en el pasado formaba parte del territorio ancestral de la etnia kawésqar llamado Tawókser (Aguilera \& Tonko 2011). En este estudio se reconoce el uso de seis especies que representa el 5\% de la flora total. Las plantas fueron empleadas por los kawésqar con fines alimentarios y para la fabricación de herramientas de caza y cestas. Seguramente el uso y conocimiento de las plantas era más amplio, pero lamentablemente no se cuenta con antecedentes actuales.

De las 9 especies con problemas de conservación halladas en el área de estudio, 8 pertenecen a la división Pteridophyta (6 a la Clase Filicopsida y 2 a la Clase Lycopsida) y una a la división Gymnospermae de la clase Pinopsida. Las especies Drimys winteri, Maytenus magellanica cambiaron su categoría de Vulnerable a Fuera de Peligro, debido a que no presentan amenaza de conservación en la Región de Magallanes, de acuerdo a la Resolución $\mathrm{N}^{0} 73$ de la Corporación Nacional Forestal, al a rtículo 19 de la Ley $\mathrm{N}^{\circ}$ 20.283 y Art. 2 transitorio.

La información entregada en este estudio puede ser utilizada como una línea base que permitirá desarrollar un plan de manejo para el uso sustentable de la biodiversidad y como una oportunidad para que otros estudios generen análisis a mesoescala de la biodiversidad aquí documentada. 
Estudio florístico del AMCP Francisco Coloane, Magallanes, Chile: Domínguez, E. \& J.C. AravenA

TABLA II. Estructura taxonómica de la flora vascular en el AMCP Francisco Coloane.

TABLE II. Taxonomic structure of the vascular flora in the AMCP Francisco Coloane.

\begin{tabular}{lcccc}
\hline Clases & Familias & GÉNEROS & Especies (N2) & Especies (\%) \\
\hline Magnoliopsida & 38 & 56 & 70 & 58 \\
Liliopsida & 9 & 26 & 35 & 30 \\
Filicopsida & 6 & 7 & 11 & 9 \\
Lycopsida & 1 & 2 & 3 & 2 \\
Pinopsida & 1 & 1 & 1 & 1 \\
\hline Total & 55 & 92 & 120 & 100 \\
\hline
\end{tabular}

TABLA III. Especies introducidas naturalizadas para la flora del AMCP Francisco Coloane.

Table III. Exotic species and invasion status for MU AMCP flora Francisco Coloane.

\begin{tabular}{ll}
\hline FAMILIA & EsPECIES \\
\hline Caryophyllaceae & Cerastium fontanum \\
Fabaceae & Lupinus arboreous \\
Poaceae & Hoicus lanatus \\
Poaceae & Poa pratensis \\
Polygonaceae & Rumex crispus \\
Rubiaceae & Galium aparine \\
\hline
\end{tabular}

TABLA IV. Tipos biológicos de la flora del AMCP Francisco Coloane.

TABLE IV. Biological types of flora AMCP Francisco Coloane.

\begin{tabular}{lcc}
\hline Forma DE VIDA & ESPECIES & (N2) ESPECIES (\%) \\
\hline Hemicriptófitas & 74 & 62 \\
Nanofanerófitas & 19 & 16 \\
Caméfitas & 7 & 6 \\
Fanerófitas & 6 & 5 \\
Epífitas & 5 & 4 \\
Terófitas & 4 & 3 \\
Hemiparásitas & 2 & 2 \\
Hidrófitas flotantes & 1 & 1 \\
Geófitas & 1 & 1 \\
Hidrófitas sumergidas & 1 & 1 \\
\hline TotaL & 120 & 101 \\
\hline
\end{tabular}

\section{AGRADECIMIENTOS}

Agradecemos el financiamiento otorgado al proyecto "Diagnóstico de la Flora, Fauna Terrestre y Aves Marinas en el Área Marina Costera Protegida de Francisco Coloane" Código BIP-N $\mathrm{N}^{\circ}$ 30061426-0 por Bienes Nacionales. A Ángel Suárez y Jaime Valenzuela por el apoyo en terreno, Carlos Olave por el desarrollo de la cartografía, Kary Haro por tabular datos, a Rodrigo Villa, Sergio Cornejo y Oscar Aguilera por sus comentarios a las versiones preliminares de este trabajo y a los revisores anónimos.
BIBLIOGRAFÍA

Aguilera, O. \& J. Tonko. 2011. Guía etnogeográfica del Parque Nacional Bernardo O’Higgins. Ed. Fundación CEQUA, $140 \mathrm{pp}$.

Baeza, M., E. Barrera, J. Flores, C. Ramírez \& R. Rodríguez. 1998. Categorías de conservación de Pteridophyta nativas de Chile. Boletín del Museo Nacional de Historia Natural 47:23-46.

Benoit, I.L. (ed). 1988. Libro Rojo de la Flora Terrestre de Chile. CONAF, Santiago, Chile, 157 pp.

Chiarucci, A. \& I. Bonini. 2005. Quantitative floristics as a tool for 
the assessment of plant diversity in Tuscan forests. Forest Ecology and Management 212:160-170.

Clapperton, C., Sugden, M.D., Kaufman, D. \& R.D., McCulloch. 1995. The Last Glaciation in Central Magellan Strait, Southernmost Chile. Quaternary Research, 44: 133-148.

Correa, N.M. (ED.). 1969. Flora Patagónica. Parte II. Colecciones Científicas del INTA. Tomo VIII. Buenos Aires. 219 pp.

Correa, N.M. (ed.). 1971. Flora Patagónica. Parte IV. Colecciones Científicas del INTA. Tomo VIII. Buenos Aires. 451 pp.

Correa, N.M. (ed.). 1978. Flora Patagónica. Parte III. Colecciones Científicas del INTA. Tomo VIII. Buenos Aires. 569 pp.

Correa, N.M. (ed.). 1984a. Flora Patagónica. Parte IV a. Colecciones Científicas del INTA. Tomo VIII. Buenos Aires. 559 pp.

Correa, N.M. (ed.). 1984b. Flora Patagónica. Parte IV b. Colecciones Científicas del INTA. Tomo VIII. Buenos Aires. 309 pp.

Correa, N.M. (ed.). 1988. Flora Patagónica. Parte V. Colecciones Científicas del INTA. Tomo VIII. Buenos Aires. 404 pp.

Correa, N.M. (ed.). 1998. Flora Patagónica. Parte I. Colecciones Científicas del INTA. Tomo VIII. Buenos Aires. 391 pp.

Dollenz, O. 1986. Relevamiento fitosociológico en la Península Muñoz Gamero, Magallanes. Anales del Instituto de la Patagonia, Serie Ciencias Naturales16: 55-62.

Domínguez, E., A. Elvebakk, C. Marticorena \& A. Pauchard. 2006. Plantas introducidas en el Parque Nacional Torres del Paine, Chile. Gayana Botánica 63(2): 131-141.

Domínguez, E. 2007. Catálogo preliminar de gramíneas introducidas en la Región de Magallanes (XII), Chile. www. chlorischilensis.cl, Año 10, $\mathrm{N}^{\circ} 1$.

Domínguez, E. 2010. Flora de interés etnobotánico usada por los pueblos originarios: aónikenk, selk'Nam, kawésqar, yagan y haush en la Patagonia Austral. Dominguezia 26 (2): 19-29.

EspinozA, N. 1996. Malezas presentes en Chile. Instituto de Investigaciones Agropecuarias Carillanca. Concepción. Editora Aníbal Pinto S.A. 219 pp.

Henríquez, J.M., E. Pisano \& C. Marticorena. 1995. Catálogo de la flora vascular de Magallanes (XII Región), Chile. Anales del Instituto de la Patagonia. Serie Ciencias Naturales 23: 5-30.

Marticorena, C. \& M. Quezada. 1985. Catálogo de la flora vascular de Chile. Gayana, Serie Botánica 42 (1- 2): 1-157.

Marticorena, C. \& R. Rodríguez. 1995. Flora de Chile Vol. 1. Ediciones de la Universidad de Concepción, Chile. 351 pp.

Matthei, O. 1995. Manual de las malezas que crecen en Chile. Alfabeta Impresores, Santiago. 554 pp.

McAleece. 1997. Biodiversity Professional Beta Program. The Natural History Museum \& The Scottish Association for Marine Science.

Moore, D.M. 1983. Flora of Tierra del Fuego. Oswestry, Saint Louis, E.E.U.U. 369 pp.

Moore, D.M. \& R.N.P. GoodAll. 1977. La flora adventicia de Tierra del Fuego. Anales del Instituto de la Patagonia, Serie Ciencias Naturales 8: 263 - 274.

Mueller-Dumbois, D \& H. Ellenberg. 1974. Aims and Methods of Vegetation Ecology. John Wyley \& Sons. 547 pp.

Novoa, P., J. Espejo, M. Cisternas, M. Rubio \& E. Domínguez. 2006. Guía de Campo de las Orquídeas Chilenas. Ed. Corporación Chilena de la Madera, Concepción, Chile. 120 pp.

NúÑEZ, E. 2008. Método para la planificación del manejo de áreas protegidas. Corporación Nacional Forestal, Santiago, Chile. 135 pp.
Parks Canada. 1997. Guía de Planificación para la elaboración de Planes de Manejo de Parks Canada. Viceministerio. Canadá. 21 pp.

Pisano, E. 1970. Vegetación del área de los fiordos Toro y Cóndor y Puerto Cutter Cove (Canal Jerónimo, Magallanes). Anales Instituto Patagonia, Punta Arenas (Chile) 1(1): 27-40.

Pisano, E. 1972. Comunidades vegetales del área de bahía Morris, isla Capitán Aracena, Tierra del Fuego (Parque Nacional Hernando de Magallanes). Anales del Instituto de la Patagonia, Punta Arenas (Chile) 3(1-2): 103-130.

Pisano, E. 1973. Fitogeografía de la península Brunswick, Magallanes. I. Comunidades Meso-Higromórficas e Higromórficas. Anales del Instituto de la Patagonia 4: 143204.

PISANO, E. 1977. Fitogeografía de Fuego-Patagonia chilena I. Comunidades vegetales entre las latitudes 52 y $56^{\circ} \mathrm{S}$. Anales del Instituto de la Patagonia 8: 121-250.

PisAno, E. 1992. Sectorización fitogeográfica del archipiélago sudpatagónico - fueguino V: sintaxonomía y distribución de las unidades de vegetación vascular. Anales del Instituto de la Patagonia, Serie Ciencias Naturales, Punta Arenas (Chile) 21:5-33

Pysek, P., D. Richardson, M. Rejmanek, G. Webster, M. WiLLIAMSON \& J. KirSCHNER. 2004. Alien plants in checklist and floras: forwards better communications between taxonomist and ecologists. Taxon 53(1): 131-143.

Ramírez, C. \& C. SAn Martín. 1993. La transformación antrópica de la vegetación de los ñadis del área Mapuche en el centrosur de Chile. Boletín Museo Regional de la Araucanía 4(1):205-214.

QIAN, H. 1999. Floristic analysis of vascular plant genera of North America north México: characteristics of phytogeography. Journal of Biogeography. 26: 1307-1321.

Ramírez, C., M. Álvarez, A. Díaz \& G. Toledo. 2006. Biodiversidad vegetal de la isla Ipún en la Reserva Nacional Las Guaitecas (Comuna de Cisnes, XI Región, Chile). Revista Geográfica de Valparaíso 37: 45-66.

Raunkiaer, C. 1934. The life forms of plants and statistical geography. Claredon, Oxford, $632 \mathrm{pp}$.

Rodríguez, R., D. Alarcón \& J. Espejo. 2009. Helechos nativos del Centro y Sur de Chile. Guía de Campo. Ed. Corporación Chilena de la Madera, Concepción, Chile, 212 pp.

Rodríguez, R., A. Marticorena \& E. Teneb. 2008. Plantas vasculares de los ríos Baker y Pascua, Región de Aisén, Chile. Gayana Botánica 65(1): 39-70.

Rozzi, R, R. Charlin, S. Ippi \& O. Dollenz. 2004. Cabo de Hornos: un Parque Nacional libre de especies exóticas en el confín de América. Anales de Instituto de la Patagonia (Chile) 32:55-62.

Secretariat of the Convention on Biological Diversity. 2008. Protected Areas in Today's World: Their Values and Benefits for the Welfare of the Planet. Montreal, Technical Series no. 36, i-vii 96 pp.

Stohlgre, T.J., Binkley, D. \& G.W. Chong. 1999. Exotic plant species invade hot spots of native plant diversity. Ecology Monographic 69: 25-46.

Valle-Levinson, A., Blanco, J.L. \& M. Frangópulos. 2006. Hydrography and frontogenesis in a glacial fjord off the Strait of Magellan. Ocean Dynamics, DOI: 10.1007/ s10236-005-0048-8. 
Villagrán, C. \& E. Barrera. 2002. Helechos del archipiélago de Chiloé, Chile. CONAF, Puerto Montt. 23 pp.

Walter, K.S. \& H. J.Gillett (eds.) (1998). 1997 IUCN Red List of Threatened Plants. Compiled by the World Conservation Monitoring Centre. IUCN, The World Conservation Union,
Gland, Switzerland an Cambridge, UK. lxiv + 862 pp. Zuloaga, F., O. Morrone \& M. Belgrano. 2011. Catálogo de las Plantas Vasculares del Cono Sur. Versión base de datos en sitio web del Instituto Darwinion, Argentina. URL: http:// www.darwin.edu.ar/Proyectos/FloraArgentina/FA.asp: Febrero 15, 2011.

Recibido: 21.06.11

Aceptado: 02.04.12 